\title{
Review \\ Closing Connectivity Gap: An Overview of Mobile Coverage Solutions for Not-Spots in Rural Zones
}

\author{
Diego Fernando Cabrera-Castellanos ${ }^{1, *(\mathbb{C})}$, Alejandro Aragón-Zavala ${ }^{1,}(\mathbb{D})$ and Gerardo Castanón-Ávila ${ }^{2,(D)}$ \\ 1 Computing Department, School of Engineering and Science, Tecnológico de Monterrey, Querétaro 76130, \\ Mexico \\ 2 Department of Mechatronics, School of Engineering and Science, Tecnológico de Monterrey, Monterrey \\ 64849, Mexico \\ * Correspondence: A00829475@itesm.mx; Tel.: +52-442-789-6898 (QR,MX)
}

\begin{abstract}
Access to broadband communications in different parts of the world has become a priority for some governments and regulatory authorities around the world in recent years. Building new digital roads and pursuing a connected society includes looking for easier access to the Internet. In general, not all the areas where people congregate are fully covered, especially in rural zones, thus restricting access to data communications and bringing inequality. In the present review article, we have comprehensively surveyed the use of three platforms to deliver broadband services to such remote and low-income areas are proposed: Unmanned Aerial Vehicles (UAV), Altitude Platforms (APS), and Low-Earth Orbit (LEO) satellites. These novel strategies support the connected and accessible world hypothesis. Hence UAVs are considered a noteworthy solution since their efficient maneuverability can aboard the rural coverage issues or not-spots.
\end{abstract}

Keywords: aerial communication; FANET; not-spots; stratospheric communication platform; UAV; UAV-Assisted network; 5G

\section{Introduction}

Coverage indicators are essential to perceive the reliability of the network in a determined area. Specifically, each country defines the best practices to determine the covered zones for their boundaries and, therefore, the appropriated thresholds associated with frequency bands. Commonly, most mobile operators offer coverage on the main urban area [1], limiting the countryside to lower bandwidth, thus reducing connection speeds [2]. Nevertheless, the interest in providing more connectivity in rural zones has grown in the last decade since the economic development will be the immediate fact.

An extensive terminology has arisen to address the coverage holes, wherein a few or even any operator guarantee its services. The Ofcom-Office of Communication of the United Kingdom-nominates them as Not-Spots. The prior entity has the intention to reach the coverage index until $95 \%$ by 2022 [3]. Several British operators $\left(\mathrm{O}_{2}\right.$, Vodafone, $\mathrm{EE}$, and Three) have implemented a sharing strategy, allowing a mutual infrastructure approach and, therefore, improving the competition in the countryside. This layout-or National Roaming - shall grant to customers in rural areas the possibility for connection to the strongest available signal, regardless of the chosen operator for these clients [3].

\subsection{Motivation}

The inequality to access to Information and Communications Technologies (ICT) resources and the lack of opportunities to reach development are the most significant drawbacks in developing countries, even though the mobile devices accounted for $87 \%$ of broadband connections there [4]. Latin America is not so far from that situation. However, most governments have changed the way to support more connectivity opportunities in the last decade. 
Within the call for promoting a prosperous society, which can curb inequality and poverty, the United Nations (UN) has considered the access to fixed-broadband Internet -under the Goal 9 outline: Industry, Innovation, and Infrastructure-a valuable resource to population's growth. By 2018, 96.5\% of the entire world population can access at least $2 \mathrm{G}$ mobile networks where LTE covers $81.8 \%$ of the [5]. In full swing of the Internet Era, not all the villages can leverage granted-by-connectivity opportunities because of the highest cost of access, unearthing the at-risk population group's unfairness.

Considering the ongoing demands of communication infrastructure, the UN Sustainable Goal 9 aims to significantly increase ICT resources access by 2020, besides struggling to hook up LDC (Least Developed Countries) with affordable technology [6]. The COVID-19 pandemic has triggered comprehensive research and investment in digitalization, namely economy and education boosting, since teleworking, video conferencing systems, and remote education have been crucial parts of pandemic and post-pandemic times.

To assess the connectivity situation around the world, the GSM Association (GSMA) provides the GSMA Mobile Connectivity Index (MCI), which measures the performance of 170 countries, based on four key enablers of mobile internet adoption: infrastructure, affordability, consumer readiness, and content and services, where the current data is by 2019 [7]. The prior institution has released The State of Mobile Internet Connectivity 2020 Report, which analyses the critical connectivity trends from 2014 to 2019 in terms of mobile internet use [4].

The coverage has not been sufficiently wide to provide the same standards compared to Europe. For instance, in [4], it is possible to check that Europe and Central Asia and North America own more of 70\% connected than the $54 \%$ of Latin America \& Caribbean. Despite this, it is crucial to stand out that the offered services have grown in the last region since its MCI overcomes a 61 score by 2019, in contrast with the obtained five years earlier: 51 [7].

Although the MCI appears to be the most significant, this is not the only affair to highlight at the moment to analyze the connectivity for particular contexts, like the countryside. Therefore, it is necessary to map out the earlier metric with each country's rural population density, discovering the most important limitations that prevent people from adopting mobile internet. Table 1 depicts both MCI and Rural Population Density (RPD)—in percentage units from the total-to analyze the gap among fifteen Latin countries themselves.

Table 1. Contrast between MCI and RPD of 15 Latin America Countries [7]

\begin{tabular}{lcc}
\hline Country & MCI & RPD \\
\hline Argentina & 67.2 & 8 \\
Bahamas & 68.7 & 17 \\
Brazil & 63.5 & 13 \\
Chile & 73.2 & 12 \\
Colombia & 63.7 & 19 \\
Costa Rica & 63.3 & 20 \\
Dominican Republic & 59.8 & 18 \\
Ecuador & 65.3 & 36 \\
El Salvador & 55.4 & 27 \\
Haiti & 32.8 & 44 \\
Mexico & 67.6 & 20 \\
Panama & 65.3 & 32 \\
Peru & 66.6 & 22 \\
Uruguay & 76.7 & 5 \\
Venezuela & 57.4 & 12 \\
\hline
\end{tabular}


Identifying the locations where the coverage is under specific boundaries appears to be suitable for sketching out the Not-Spots presence in these contexts. Therefore, Figure 1 charts the correlation between the total population and the coverage density, segregated by the mobile networks' generation, from $2 \mathrm{G}$ to novel $5 \mathrm{G}$, in two specific countries of the target region: Mexico and Colombia. This purpose aims to recognize the coverage gap inside the mentioned countries. Besides, it likely identifies regions whose population can not access nor Voice nor Data services.

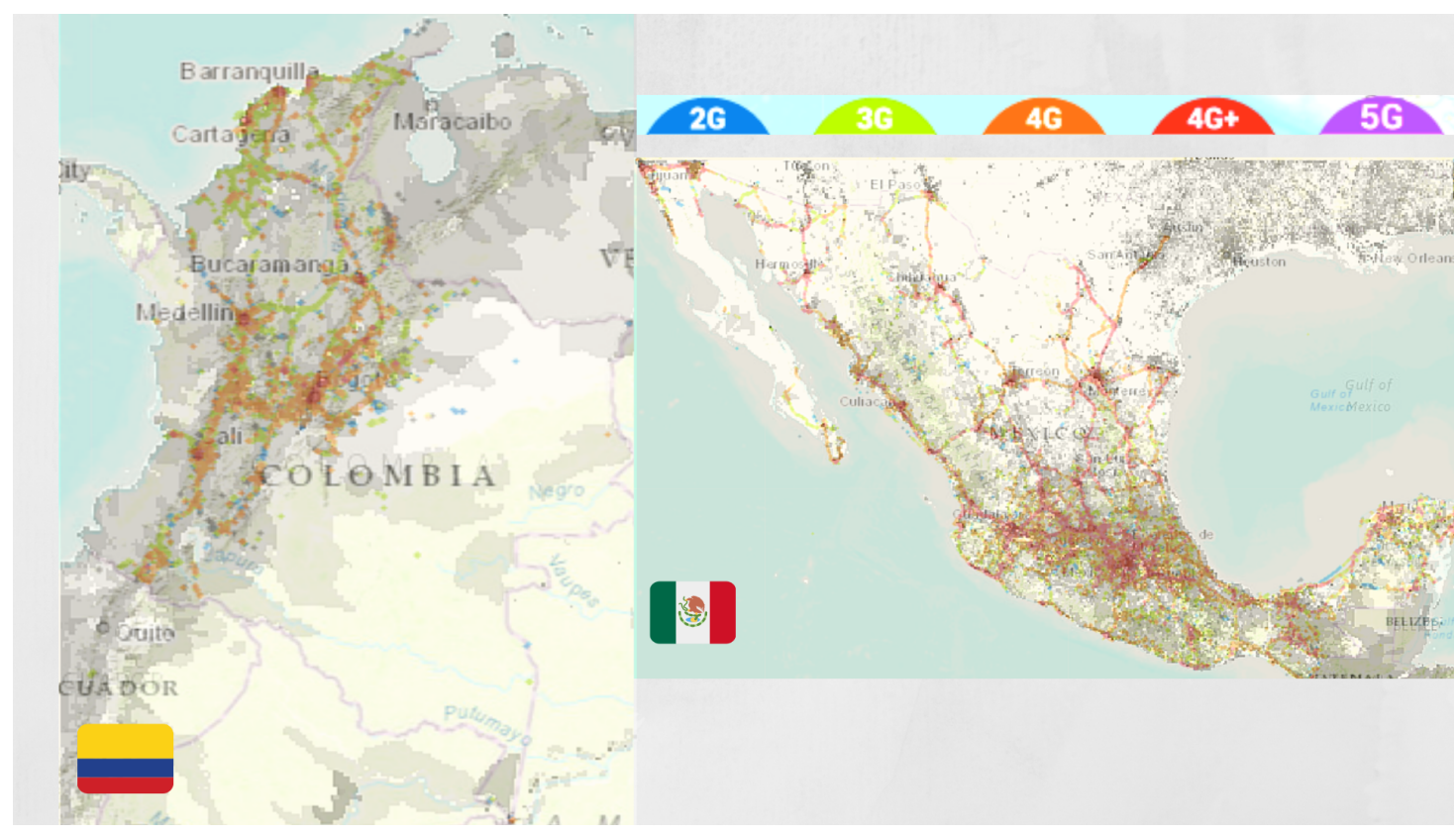

Figure 1. Correlation between Population and Current Mobile Networks Coverage in both study cases

\subsection{Paper Outline}

We have reviewed several strategies that pursue new connectivity standards by expanding the network coverage, especially for developing countries, compared with developed countries, such as European ones. These approaches aim to list the possible technologies that will improve the connectivity in the rural zones after studying the researched options in the alternative deployment of networks to optimize those regions.

After state the motivations and the principal purposes roughly, we outlined the article as follows: Section 2 presents a perspective by the network environment (outdoor and indoor), highlighting the solutions that engage emergent services like the Internet of Things (IoT). Section 3 sketches out the possible researched technologies to enhance the coverage in rural zones and achieve high Quality of Service (QoS) and the network's throughput. Sections 4 and 5 sets forth the discussion and conclusions about the assessed solutions in prior sections, besides bearing in mind new research opportunities in this field. To this end, Figure 2 shows the overall organization of the cited references in this review article.

\section{The Rural Paradigm Shift}

Under the perspective of granting better connectivity standards in the countryside, it is adequate to set forth the differences among several best-fitted technologies to find an optimal solution. The first approach is a suitable onset to focus on the mobile network connection optimizing for rural populations, and self-steady links for IoT terminals, whether involving the new communication tendencies, such as Device-toDevice communications (D2D) or even 5G [71]. 


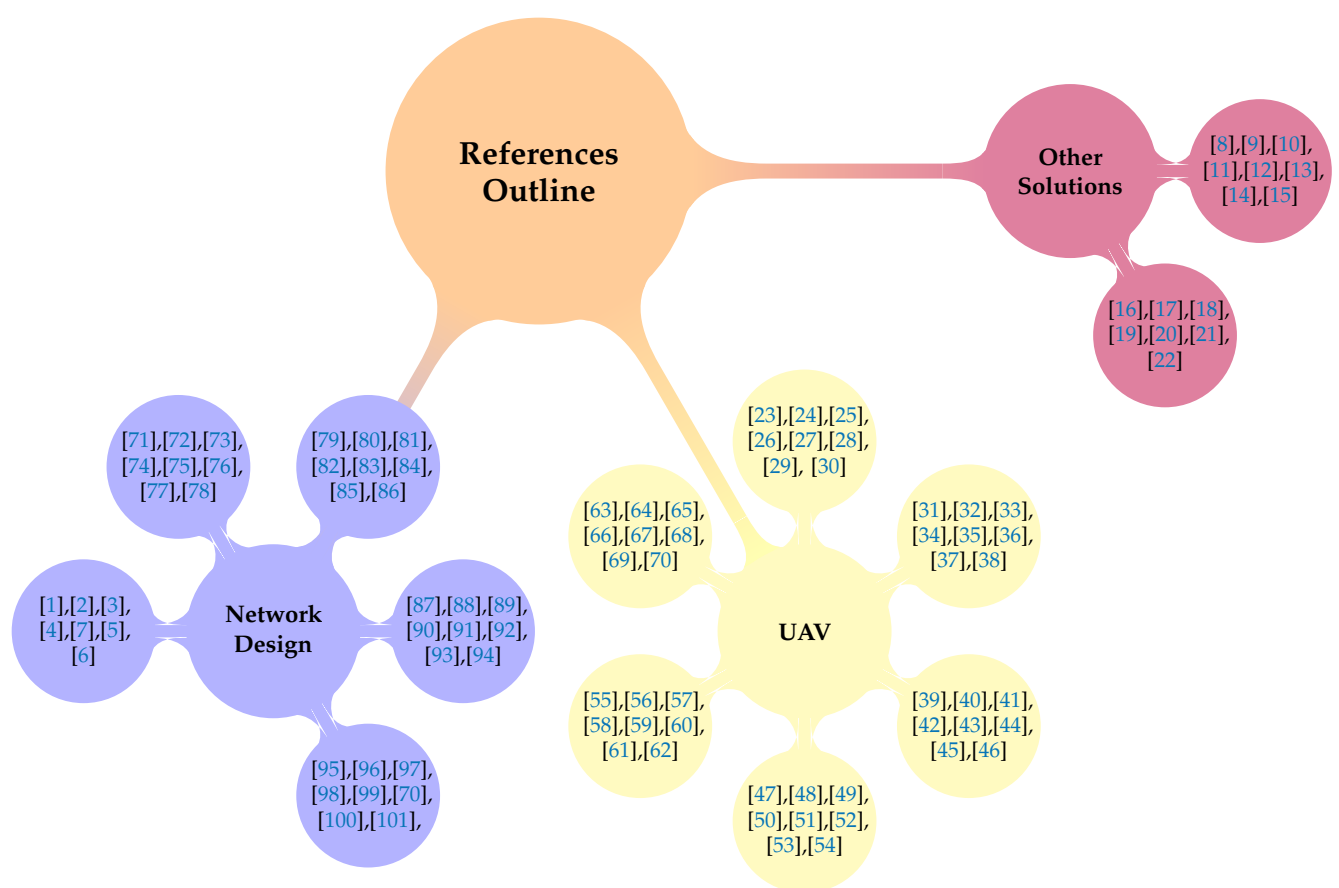

Figure 2. Categorized References Used in Our Survey

Outdoor and indoor environments require the above aims to lift specific responses within the rural population needs. The outdoor schemes consider current traffic estimation of the mobile network by algorithmic focusing since it may provide the proper breakdown to determine the cells coverage capacity [72]. About indoor environments, achieving an extended coverage based on Ad-Hoc Networks by lower frequency bands involving repeaters would be suitable [86]. The Subsections 2.1 and 2.2 will cope with the solutions for both cases.

\subsection{Outdoor Perspective}

Gatwaza et al. in [72] highlighted that traffic is an outstanding factor to dimension the current mobile networks. In isolated zones, the challenge lies in finding out how to fix the maximum coverage per single base station by the complex topography and the highly dispersed population distribution [74]. Information of geographical distribution is quite relevant for Internet Service Providers (ISP) since it allows the estimation of the areas that deserve specialized deployment toward determining the under-requirements system capacity [75].

The coverage parameter defines the network scope, leading to the expected enhance for lower-connectivity regions. Consequently, the channel's propagation parameters, such as Path Loss Exponent and Losses, are essential for coverage and quality analysis. For instance, CDMA and AMPS cells may overlay the target geographical areas to carry the information among the remote Base Stations (BS) appropriately [76]. Other alternatives include the use of WiMAX-IEEE 802.16 — set of standards [77] and the TV White Spaces (TVWS) [78] to enable a ubiquitous network.

At the onset of century XX, development countries evaluated options to achieve better QoS in rural zones. One of them was implementing high-quality-in-car mobile services without the implementation of new cell sites. Thus there was a possibility to raise the roadways coverage area through antenna arrays set over constant on-ways cars. This advance might have allowed minimizing cost surround no installation of more BSs. Furthermore, it would give steps forwards due to implementation over that dynamic CDMA signals, eradicating AMPS services [76].

With the massification of novel technologies, e.g., 5G and IoT, for urban zones, the idea includes analyzing other low-deployment cost options, such as FTTx. Araujo et 
al. pointed out in [79] that services on FTTC (Curb) would be 70\% cheaper than 5G implementation and 20\% less expensive than FTTH (Home). Although the main idea is boosting the countrysides as high-opportunities potential zones, non all operators expect to invest in high-cost infrastructure for low-dense populations because its rollout may cost $80 \%$ higher than in urban zones [80].

So far, several approaches have arisen regarding reach the desired coverage index. Knowing that $5 \mathrm{G}$ services are not considered for the countryside yet, IoT services are limited in high-reliable networks. More quantity of unfolded BSs, more coverage index may be reached, increasing the efficiency [79]. The BS coverage area is more significant than $0.5 \mathrm{Km}$, and having enough overlapped-with-adjacent cells will ensure the quality of roaming at the maximum allowable distance among them [81].

In mobile networks, the handover parameter is triggered when a User Equipment (UE) detects a better signal strength of the neighboring cells [1], but it can also regard the non-convergence in the case of rural zones. Thus, identifying the BS coverage area at network planning is a relevant part of the design process. The 3G services may be the first technology to implement in the countryside since it is possible to monitor the network parameters - as coverage and cell capacity_by desiring appropriate Signal-toNoise rates (SNR) and QoS index. It is important to recall that the rural connectivity gap is proportionally greater for low-income households [82].

After reviewing some references, we found that Stratospheric Communication Platforms (SPC) have been trending in the last decade for outdoor solutions [8,84]. The Loon Project was looking for building a new layer of the connectivity ecosystem in the stratosphere based on weather balloons with distributed-self optimization [83]. The Loon LLC group tackled the challenge of extending internet access worldwide based on this approach until the project was closed down in $2021[9,102]$. Another intended sample was Facebook Aquila, yet it has collapsed in 2018 [103].

Another kind of alternatives to cover rural populations includes the use of LEO satellites. Besides, LEO and SCPs significantly enable the coverage increase and do not require new terrestrial towers. Therefore, this will offer a highly reliable data rate service, demanding simple but special maintenance attention about its tracing [85]. Figure 3 states a feasible implementation of the reviewed solutions in the countryside for outdoor, aiming to develop the new tendencies considered in the Subsection 2.3.

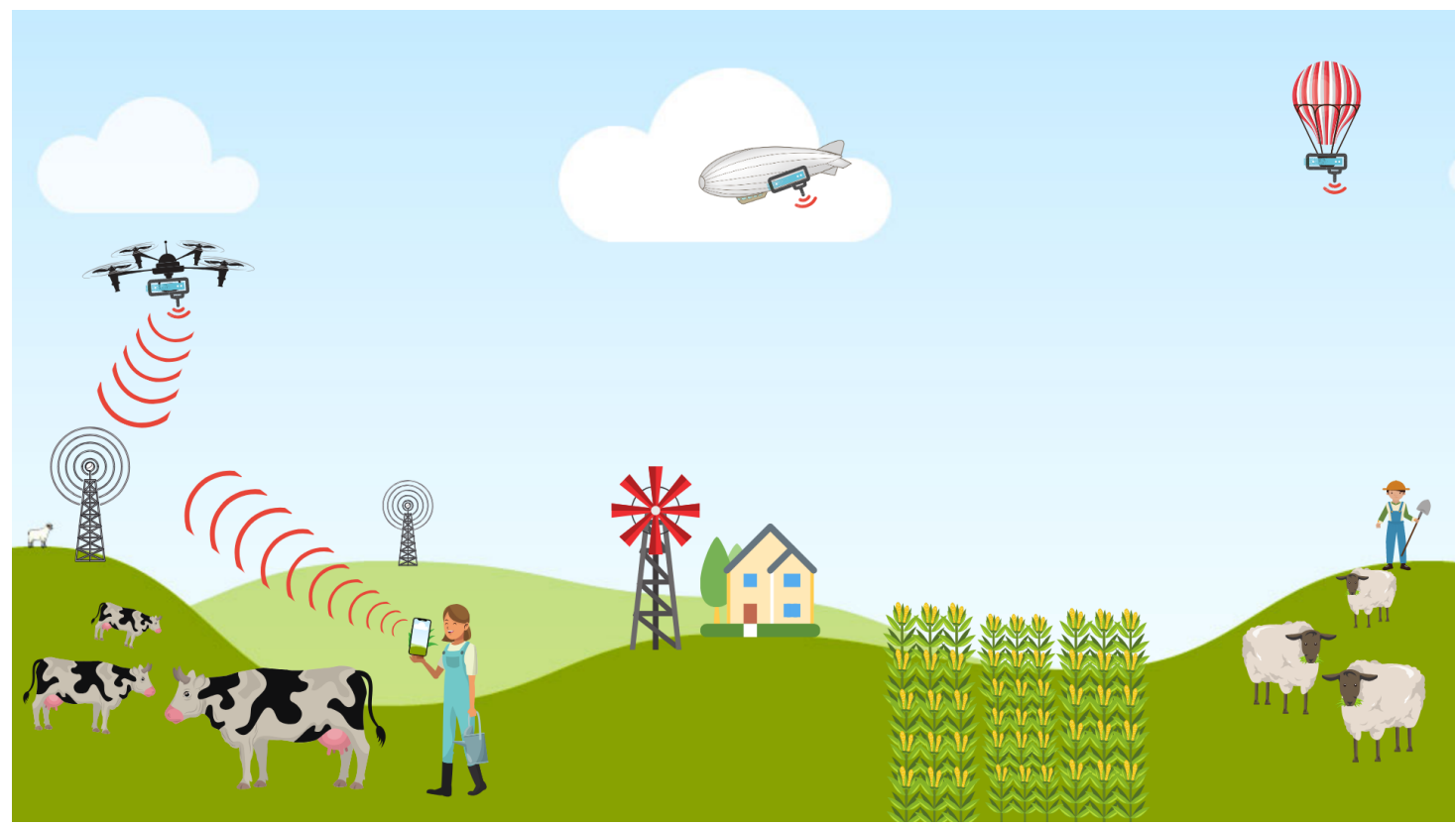

Figure 3. Some Solutions for Outdoor Networks Issues 


\subsection{Indoor Case}

Indoor-improving techniques outline the strategies that enhance the user experience inside closed spaces. Therefore, there is more interference by the physical obstacles. This case requires evaluating the best estimation of indoor coverage provided, looking for optimal system planning. The feasibility to implement algorithmic solutions based on the UE location estimation appears to be challenging since their location accuracy depends on the integrated sensors in the devices by authors said in [73].

The satellite-based networks and other high-altitude platforms suffer excess losses because the slant path intersects several obstructions than terrestrials. Nevertheless, using repeaters at lower frequency bands-despite the bandwidth limitation-can fulfill the requirements demanded from the users [86]. These devices are low-cost and readily available, hence boosting signal propagation meanwhile enhancing indoor coverage may be achieved. Figure 4 shows a potential indoor-improvement deployment for a satellite-based backhaul.

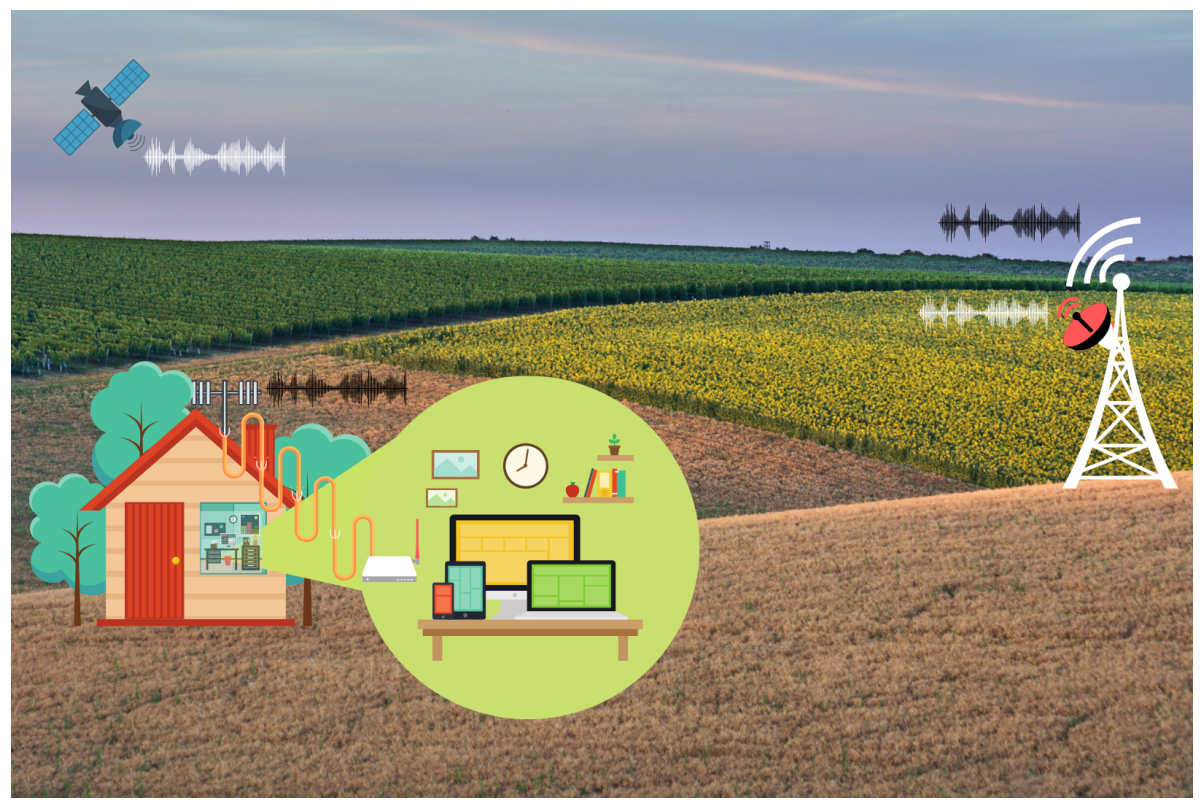

Figure 4. Indoor Solution for a Satellite-Based Network

\subsection{New Services}

A few years ago, trending services such as IoT and 5G were considered challenging to implement in rural areas, especially for Latin America, because there were no considerations to grant a reliable and high-traffic supported backhaul network. Nevertheless, these paradigms would hook up dispersed nodes located in remote zones nowadays, with staggering downlink/uplink rates, aiming to accomplish the requirements for MTC and Narrowband-Internet of Things (NB-IoT) [87].

IoT promises to be a suitable technology to upgrade the countryside-a stable network may be guaranteed meanwhile-following the massive number of connected things and the heterogeneous nature of IoT devices. On the other hand, there is the incursion of MTC application domains, such as agriculture management, transportation, logistics improvement, and crop automation, being one of the fastest-growing telecommunications technologies, especially in urban contexts [88]. LTE-based MTC addresses advantages in increasing the capacity, the traffic response, and the spectral efficiency [89].

Diverse strategies have arisen from assessing the most appropriate technologies to furnish high-speed broadband and reach the desired standard like the service speed, set up at $30 \mathrm{Mbps}$ in European rural areas. Ioannou et al. in [90] state that FTTdp (Distributed Point) solution using G.fast standard performs a cost-effective alternative to 
VDSL, which the last is the most widespread technology in Europe to grant connectivity in the countryside for now. The authors acknowledge that FTTdP G.fast readily enables bandwidth upgrade, but the model is non-cost-efficient to invest in geographically sparse populations $[79,80]$.

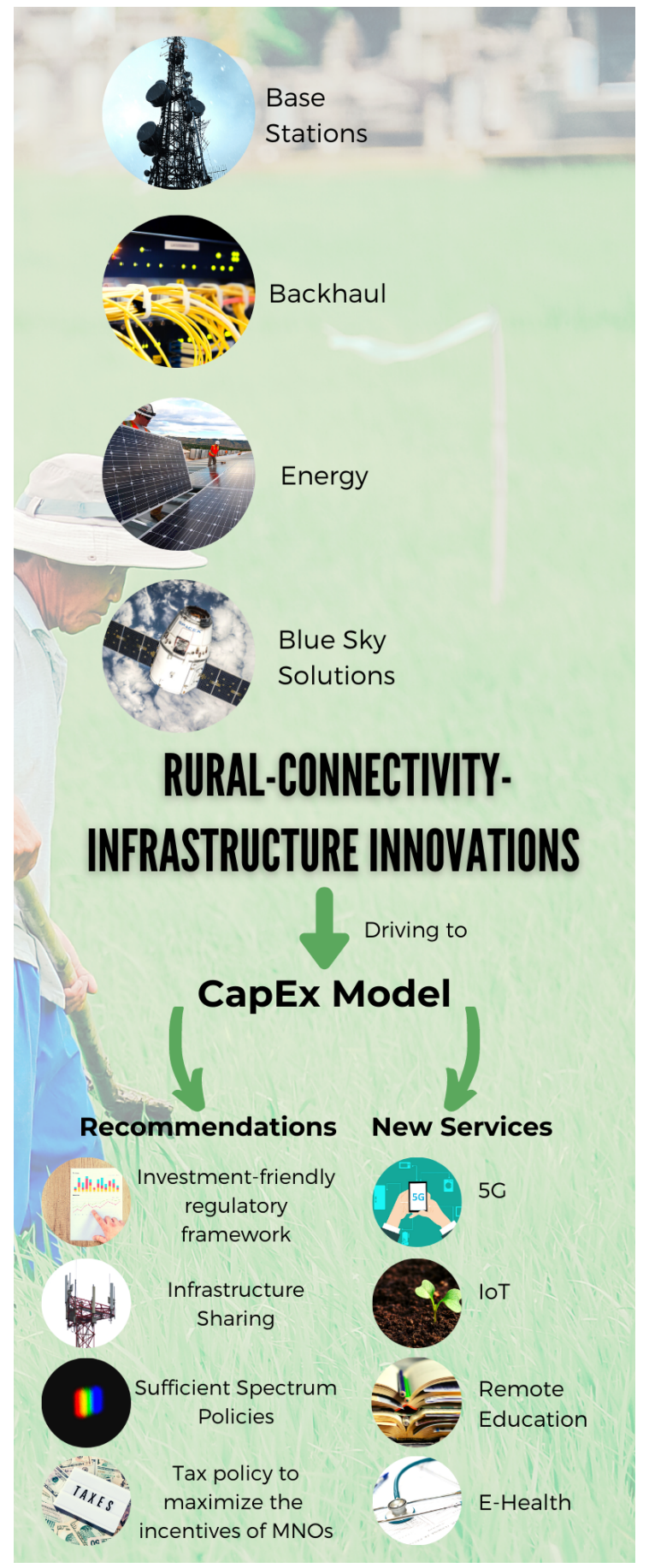

Figure 5. Innovations for Rural Connectivity Infrastructure
Consequently, LTE Fixed Wireless Access Networks (LTE FWA) could be an available, attainable solution, bearing in mind extensive LTE infrastructure in a significant rural part of the world. Whether new-emerged 5G standards are desirable to implement, we can upgrade the LTE FWA through the LTE-NR model, a tight interaction between LTE and the New Radio system. The also known model EUTRA-NR Dual connectivity-or EN-DCallows benefits in aspects of user throughput in both low and high traffic load conditions [91].

Foreseeing the inclusion of the services mentioned above, the design of Internet access solution should be engaged with the three main factors as the authors outlined in [93]:

- affordability, for avoiding undue hardships employing reliable networks.

- social shareability, to gain access through selfless (shared) connections.

- geographical network coverage, where networks allow the user's mobility by themselves.

Complementary, the requirements on ubiquitous coverage will not follow the one-size-fits-all standard to pursue a more connected rural society [92].

Figure 5 summarizes the information granted by the GSMA's reports [94,95], which attempt to state the main driven innovations through an improved roll-out in three foremost aspects:

- BS infrastructure, far-flung from the traditional macrocells model.

- Backhaul planning, avoiding the higher cost than urban deployments.

- energy, mixing up with renewable sources.

- Blue Sky solutions, although those remain in the proof-of-concept stage.

These innovations will move beyond the traditional business model-such as CapEx - where the local governments should create new regulation principles to harvest investment in network infrastructure. 


\section{Potential Solutions}

There are several challenges to face in rural areas in terms of reliable and enhanced mobile networks. This need triggers the state-of-art study of the diverse network models for the countryside to introduce ubiquitous solutions. All the time and wherever the connectivity shall be available to attend to the population's demands in a fully connected society's eagerness.

By the first attempt to overcome the likely hardships, such as the lack of population enough to deploy infrastructure, adaptive solutions struggle with the current Mobile Network Operators (MNO) unfolding. The new platforms or devices-that enhance coverage and other rural Key Performance Indicators (KPIs) - leverage practical alternatives for outdoor environments.

There have been studies that cater to the rural coverage through TVWS-spectrum sharing approach where uses free UHF band channels from analog switch-off in a specific time, and space location by the authors says in [78]. Indeed, the primary user (PU) exclusively uses the frequency resources on the bands $470 \mathrm{MHz}$ and $710 \mathrm{MHz}$.

On the other hand, S. Hasan et al. [96] aimed to recover the GSM whitespace-or the non-actively-used and licensed GSM spectrum-to support the dynamic spectrum sharing, hence achieving a suitable QoS would not be attached to the low throughput and high latency. Regardless, other kinds of solutions have arisen so far to aim for the fully connected countryside.

In the following subsections, several trustworthy approaches will be set forth for diverse rural outdoor solutions, such as Unmanned Aerial Vehicles (3.1), Low Altitude Platforms, and High Altitude Platforms, and Satellites (3.2). Then, Figure 3 graphically summarizes the solutions as mentioned above to cope with the rural not-spots.

\subsection{UAV-Assisted Networks}

Nowadays, uncrewed aircraft have commercial uses and have enabled new research interest and innovation toward improving connectivity. The smaller is the airship, the better is the performance to bestow coverage, especially for isolated areas. In this case, the drone industry has addressed several civil instances and applications beneath an affordable and straightforward aim: leveraging UAVs' maneuverability to readily provide connectivity as an off-the-shelf alternative within the current MNOs infrastructure.

Historically, the first purpose for Unmanned Aerial System (UAS) was for military and surveillance fields. During the second half of the XX century, the Warfighter's Internet yielded a reliable and readily deployment of UAV-based Ad Hoc Network to boost the backbone communications [24]. This exploited UAS approach led to higher throughput standards. Therefore a network-centric UAS operation concept arose beyond the military and political boundaries, consequently adopted for civil and economic interests. In a nutshell, the uncrewed airships outpaced beyond the soldiery endurance.

Since an expedited drone spread-over-the-air has lifted recently, the need for regulating them has arisen as well, complying with the safety standards, even though they reached lower altitudes than other larger kinds of aircraft. Therefore, the Global Unmanned aircraft system Traffic Management Association — or GUTMA — appears to foster the trustworthy, secure, and efficient integration of UAS into global airspace, addressing drone stakeholders practices-defined as UTM stakeholders - by close cooperation and continuous flights information management [100].

To lend a collaborative and innovative community for UTM stakeholders, GUTMA encourages the governments to adopt operation-centric, heading for safe, fair, and secure deployment of UTM solutions. Besides, for allowing full integration of UTM services with current network infrastructure, the first step should foresee the digitalization needs of UAS technology trends [101]. Once set it forth, Table 2 compiles some of the key specifications for the UAV-assisted network in line with the deployment scenario, namely urban, suburban, and rural contexts. 
Table 2. Context-based Specifications for UAV Networks

\begin{tabular}{|c|c|c|c|c|c|c|c|c|}
\hline \multirow[b]{2}{*}{ Scenario } & \multicolumn{5}{|c|}{ Network Parameters } & \multicolumn{3}{|c|}{ Context } \\
\hline & $\begin{array}{l}\text { LHT } \\
{[\mathrm{m}]}\end{array}$ & $\begin{array}{l}\mathrm{UHT} \\
{[\mathrm{m}]}\end{array}$ & $\mathrm{BMP}$ & LOS & NLOS & $\begin{array}{l}\text { Use } \\
\text { Case }\end{array}$ & $\begin{array}{c}\text { Network } \\
\text { Configuration }\end{array}$ & $\begin{array}{c}\text { Flight } \\
\text { Time [min] }\end{array}$ \\
\hline UMa-AV & 22.5 & 100 & & $X$ & & $\begin{array}{l}\mathrm{HD} / \\
\mathrm{M} 2 \mathrm{H}\end{array}$ & $5 G$ & TBD \\
\hline UMi-AV & TBD & TBD & & & $x$ & $\mathrm{M} 2 \mathrm{H}$ & LTE/ & $15-45$ \\
\hline RMa-AV & 10 & 40 & $x$ & $x$ & & $\begin{array}{c}\text { L2M/ } \\
\text { LD }\end{array}$ & LTE+ & $60-180$ \\
\hline
\end{tabular}

The gathered information in Table 2 divides up the network features into two correlated fields: the target scenarios and the use case context. Concerning the first, Muruganathan et al. approached the stakeholder populations in [70] and their LTE network's technical deployment in environments such as Urban-macro with aerial vehicles (UMa-AV), Urban-micro with aerial vehicles (UMi-AV), and Rural-macro with aerial vehicles (RMa-AV). The second considers zones density, emphasizing the Highest (HD), the Medium-to-High (M2H), the Low-to-Medium (L2M), and the Lowest (LD) [98].

An analysis of coverage issues should extend the operational scope through defined network architecture to successfully deploy aerial communications. A first option unleashes a unique UAV model by hooking up one or several Ground-BS (GBS) and the drone acting as a relay node into the network. Secondly, a swarm of drones seems suitable to cover a vast extension or rural dispersed nodes, creating a solid construction of Flying Ad-Hoc Networks (FANET) networking.

The last strategy outpaces the challenging issues that Mobile Ad-Hoc Networks (MANET) were tackled in terms of communication range since a ground node can indirectly communicate with other hops through several aerial relay nodes such as UAVs [44]. Since an expedited drone spread-over-the-air has lifted recently, the need for regulating them has arisen as well, complying with the safety standards, even though they reached lower altitudes than other larger kinds of aircraft. Therefore, the Global Unmanned aircraft system Traffic Management Association—or GUTMA—appears to foster the trustworthy, secure, and efficient integration of UAS into global airspace, addressing drone stakeholders practices-defined as UTM stakeholders - by close cooperation and continuous flights information management [100].

To lend a collaborative and innovative community for UTM stakeholders, GUTMA encourages the governments to adopt operation-centric, heading for safe, fair, and secure deployment of UTM solutions. Besides, for allowing full integration of UTM services with current network infrastructure, the first step should foresee the digitalization needs of UAS technology trends [101]. Once set it forth, Table 2 compiles some of the key specifications for the UAV-assisted network in line with the deployment scenario, namely urban, suburban, and rural contexts.

The concept of FANETs has arisen in the literature to top off with a particular form of Vehicular Ad-Hoc Networks (VANET) communications and addressing for scalable, reliable, real-time peer-to-peer mobile ad-hoc networking between aerial and ground nodes [55]. Table 3 relates some UAV-based communication surveys, where the authors have thoroughly reviewed the UAS modeling strategy in fields such as civil, security, traffic management, among others.

The approaches, as mentioned earlier and among others, are comprehensively explained in Table 4 and Table 5. The first acknowledges the literature of UAV-based networks between twenty and five years ago, which states the strategies that the cited authors assessed for expanding MANET coverage primarily by algorithmic solutions. The second leads our survey to the outstanding aim: to gauge the promising models 
Table 3. Some Surveys of UAV-based Communications

\begin{tabular}{|c|c|}
\hline Publication & Brief Summary \\
\hline $\begin{array}{l}\text { Mozaffari } \\
\text { et al. } \\
{[43]}\end{array}$ & $\begin{array}{l}\text { A fair of potential benefits and } \\
\text { applications of UAV-based } \\
\text { communications in the enhancing } \\
\text { coverage, capacity, and reliability of } \\
\text { wireless networks eagerness. }\end{array}$ \\
\hline $\begin{array}{l}\mathrm{Li} \\
\text { et al. } \\
{[46]}\end{array}$ & $\begin{array}{l}\text { A noteworthy integration of } 5 \mathrm{G} \\
\text { technologies with UAV communications } \\
\text { networks upon an emerging } \\
\text { space-air-ground integrated network } \\
\text { architecture. }\end{array}$ \\
\hline $\begin{array}{l}\text { Fotouhi } \\
\text { et al. } \\
{[48]}\end{array}$ & $\begin{array}{l}\text { A development summary promotes the } \\
\text { smooth integration between UAVs and } \\
\text { cellular networks without a } \\
\text { one-size-fits-all but affordable model. }\end{array}$ \\
\hline
\end{tabular}

\section{Approaches Fields}

- The key UAV challenges hold 3D

deployment, performance analysis, channel modeling, and energy efficiency.

- A comprehensive overview on potential applications, chief research directions, challenging open problems, among others.

\section{- Space-air-ground integrated network} envisions for Beyond-5G

Communications.

- 5G techniques for physical and network layer of UAV scheme, and joint communication, computing and caching.

- The authors surveyed the interference issues, and potential solutions on UVA-based flying relays and BS approaches.

- The article sets forth the new regulations and protocols to grand the cyber-physical security in both aerial nodes and UEs.

\begin{tabular}{ll}
\hline Shakhatreh & An exhibition of next large revolution in \\
et al. & civil applications by introducing UAV \\
[68] & technologies to state feasible research \\
& trends and future insights.
\end{tabular}

- Addressed civil applications: Road traffic's real-time monitoring, wireless coverage, remote sensing, search and rescue, surveillance, civil infrastructure, among others.

- Discussed key challenges: Charging, collision avoidance, security, and networking.

\begin{tabular}{|c|c|c|}
\hline $\begin{array}{l}\text { Khawaja } \\
\text { et al. } \\
{[69]}\end{array}$ & $\begin{array}{l}\text { Modeling of Air-to-Ground (A2G) } \\
\text { propagation channels in designing and } \\
\text { evaluating stages of UAV communication } \\
\text { links attempts to improve the AG channel } \\
\text { measurement campaigns. }\end{array}$ & $\begin{array}{l}\text { - AG wireless propagation channel } \\
\text { research includes payload } \\
\text { communications and control and } \\
\text { non-payload (CNPC) networks. } \\
\text { - The AG channel study tackles } \\
\text { limitations as large and small scale } \\
\text { fading. }\end{array}$ \\
\hline $\begin{array}{l}\text { Hayat } \\
\text { et al. } \\
{[37]}\end{array}$ & $\begin{array}{l}\text { The aerial network missions should vary } \\
\text { according to the civil application aims. }\end{array}$ & $\begin{array}{l}\text { - Search and Rescue Coverage } \\
\text { - Network Coverage } \\
\text { - Delivery and Transportation } \\
\text { - Construction }\end{array}$ \\
\hline
\end{tabular}

for rural communications, raising the current cellular infrastructure, or even adopting a new topology for ubiquitous coverage.

\subsubsection{Regulation}

The 3GPP Association mainly tackles the protocols and regulations for UAS-FANET communication beneath the addressed need of the quickly maturing sector [99]. Consequently, in the eagerness to state new studies and new features for a safe operation, there has been joint work with GUTMA, even involving the novel 5G framework use cases. To best awareness, Figure 6 introduces the areas that are being addressed in the latest 3GPP Releases, from Release 15 to Release 17. 
Table 4. Phases of UAV-Based Network Models

\begin{tabular}{|c|c|c|c|}
\hline PHASE & APPROACHES & $\begin{array}{l}\text { STRATEGIES / } \\
\text { MODELS }\end{array}$ & $\begin{array}{c}\text { ADVANTAGES / } \\
\text { FINDINGS }\end{array}$ \\
\hline \multirow{10}{*}{$\begin{array}{l}\text { Early: } \\
<2011\end{array}$} & \multirow{3}{*}{$\begin{array}{l}\text { Military } \\
\text { Services }\end{array}$} & Airborne Communication Nodes to form a backbone network for Warfighter's Internet [24]. & $\begin{array}{l}\text { - Allowing connection for separated forces } \\
\text { Reliable and easily deployed }\end{array}$ \\
\hline & & $\begin{array}{l}\text { The biologically inspired-metaphor algorithm of bird flocking for UAV nodes' placement and } \\
\text { motion, adapting their mobility }[26] .\end{array}$ & $\begin{array}{l}\text { - Especially useful for rugged and mountainous terrains with heavy signal attenuation. } \\
\text { - Achieving a stable connection and load balancing. }\end{array}$ \\
\hline & & $\begin{array}{l}\text { Dynamically placing UAVs considered as relays nodes to provide full connectivity in a disconnected } \\
\text { ground MANET through heuristic and algorithmic approach [31]. }\end{array}$ & $\begin{array}{l}\text { - Location tracking that allows an optimal interaction between ground nodes and UAVs without introducing new } \\
\text { MANET protocols. } \\
\text {. Cost reduction based on finding the minimum number of needed UAVs. }\end{array}$ \\
\hline & \multirow{4}{*}{$\begin{array}{l}\text { Integrated } \\
\text { Architecture }\end{array}$} & $\begin{array}{l}\text { Two-level Satellite empowered architecture (HAPs/UAVs + Satellite) to improve the limited coverage, } \\
\text { guaranteeing superior bandwidth access }[33,36] \text {. }\end{array}$ & $\begin{array}{l}\text {-Allowing interconnection with remote locations. } \\
\text {. Enhancing hot-spot coverage with low latency rates. } \\
\text {. Mitigation of shadowing impairments through a HAPs/UAVs repeaters-configuration. }\end{array}$ \\
\hline & & $\begin{array}{l}\text { Implementation of UAV-HALE (UAV-High Altitude Long Endurance) platform as a base station } \\
\text { with an adaptive antenna array [23]. }\end{array}$ & $\begin{array}{l}\text { - Covering rural low-densely populated areas and isolated-by-relief regions. } \\
\text { - Support the telecommunication system in emergencies. } \\
\text {-Assist hot-spots traffic with a lower cost solution } \\
\text { - Provide higher QoS, increasing capacity and keeping lower computational complexity. }\end{array}$ \\
\hline & & $\begin{array}{l}\text { An algorithmic solution to state and hedonic coalition formation, consisting of a determined number of UAVs } \\
\text { continuously collecting packets from task arrays [28]. }\end{array}$ & $\begin{array}{l}\text { Performance improvement, based on the self-organization of air nodes and tasks into independent coalitions. } \\
\text {-UAVs can assess the decision to act as collectors or relays(to enhance wireless transmission). } \\
\text {. Suitable model to tackle several aims as surveillance or wireless monitoring. }\end{array}$ \\
\hline & & $\begin{array}{c}\text { Evaluation of A2G links coverage using UAVs at altitudes up to } 500 \mathrm{~m} \text {, performing as a radio relay } \\
\text { plattorms in low RF environments }[29,32]\end{array}$ & $\begin{array}{l}\text { Support over } 90 \% \text { coverage of the ground receivers within } 10 \mathrm{~dB} \text { of LOS Path Loss. } \\
\text { - Excellent connectivity for low flying UAV in limited urban areas considering SWAP, } \\
\text { even for buildings-blocked receivers. } \\
\text {. For higher altitudes, the coverage becomes homogeneous in rural zones. }\end{array}$ \\
\hline & \multirow{5}{*}{$\begin{array}{l}\text { MANETs } \\
\text { Upgrade }\end{array}$} & $\begin{array}{l}\text { UAV-assisted MANET model, which is rooted in } 4 \text { connectivity regards: global message (successful propagation } \\
\text { to all nodes), worst-case (dividing up a close network), bisection (division cost), and k-connectivity } \\
\text { (failed nodes threshold before a disconnection) [25,27]. }\end{array}$ & $\begin{array}{l}\text { The aerial nodes can generate, receive, and forward data packets; or improve network connectivity and } \\
\text { availability. } \\
\text {-The model will achieve better QoS and coverage. } \\
\text {-As the proposed method, an adaptive heuristic algorithm can provide a simple solution and reach a better } \\
\text { performance. }\end{array}$ \\
\hline & & $\begin{array}{l}\text { Performance assessment of Ad Hoc routing protocols, like GPRS, OLSR, and AODV, in the context of swarms } \\
\text { of UAVs, also considering the relative location of destination nodes [30]. }\end{array}$ & $\begin{array}{l}\text { Maximize the throughput with a minimum number of neighbors into the swarms to ensure connectivity. } \\
\text { Minimize power consumption and optimize the loiter time to prevent cross-interference and redundant } \\
\text { transmissions through spatial multiplexing technique. }\end{array}$ \\
\hline & & $\begin{array}{l}\text { Ad-Hoc UAS-Ground Network (AUGNet) solution, where an Unmanned Aircraft provides } \\
\text { additional connectivity for ground nodes, driving into shorter routes with better throughput [34]. }\end{array}$ & $\begin{array}{l}\text { Improve the connectivity at the network coverage boundary. } \\
\text { Introduce the net-centric UAS operation concept, a tight coupling between communications, mobility, } \\
\text { and takk fulfillmment. }\end{array}$ \\
\hline \multirow{9}{*}{$\begin{array}{l}\text { Medium: } \\
2011-2016\end{array}$} & & $\begin{array}{l}\text { Mobility strategy for UAV-compound MANET to support communication data flow between ground nodes in a } \\
\text { dynamic topology network [35]. }\end{array}$ & $\begin{array}{l}\text {-Provide the most appropriate air nodes position that maximizes network performance. } \\
\text { UAV nodes can flexibly communicate with ground nodes in the LOS, covering a greatly extended area. } \\
\text {. Ground nodes periodically grant their communication status to the air-backbone to find the best mobile strategy. }\end{array}$ \\
\hline & & $\begin{array}{l}\text { Analysis of the coverage problem to aboard several issues in UAV-FANETs, expecting } \\
\text { to extend their operational scope and range, and a reliable response time }[44,55,60] \text {. }\end{array}$ & $\begin{array}{l}\text {-The solid construction of FANET networking standards will lead to scalable, reliable real-time } \\
\text { peer-to-peer, now-form MANETs. } \\
\text {-Aim to the robustness of the coverage algorithms, considering the several constraints in these kinds of networks, } \\
\text { especially for UAVS fleets. } \\
\text { - Cooperating UAV form aims to increase reliability for aerial missions, ensuring the connectivity of non-LOS } \\
\text { systems. }\end{array}$ \\
\hline & \multirow[t]{3}{*}{$\begin{array}{l}\text { Connectivity/ } \\
\text { Coverage } \\
\text { Enhancement }\end{array}$} & $\begin{array}{l}\text { Approach established on a neural-based cost function to improve coverage and boost capacity into geographical } \\
\text { areas subject to high traffic demands [45]. }\end{array}$ & $\begin{array}{l}\text { - Provide reliable multi-connectivity using UAS overview as relays between a disconnected network and } \\
\text { enhance connectivity. } \\
\text { - The model can provide better capacity, reliability, and prolonged connectivity to tackle the inefficiency in } \\
\text { handling macro cellular networks traffic demands. }\end{array}$ \\
\hline & & $\begin{array}{l}\text { The connectivity-based mobility model (CBMM) compares coverage and connectivity performance, looking for an } \\
\text { optimal tracing and sense of a given area [53]. }\end{array}$ & $\begin{array}{l}\text { - Monitor inaccessible or dangerous areas to deliver information with lack-of-infrastructure regions. } \\
\text { CBMM allows adapting air nodes direction to maintain steady links to ground stations or their neighbors. } \\
\text { Reduce the overlap between covered areas, using an efficient and limited number of UAVs with a specific } \\
\text { spatial density. }\end{array}$ \\
\hline & & $\begin{array}{l}\text { Efficient 3D deployment of multiple UAVs as portable Base Stations, seeking the downlink coverage performance's maximization, } \\
\text { whereas using a minimum transmit power and directional antennas [40]. }\end{array}$ & $\begin{array}{l}\text { Aerial Base Stations have a higher chance of LOS links to ground users. } \\
\text {-UAV can readily move and have a flexible deployment to provide rapid, on-demand communications. } \\
\text { Using directional antennas, the model may enhance UAV-based networks because of effective } \\
\text { beamforming schemes. }\end{array}$ \\
\hline & \multirow[t]{2}{*}{$\begin{array}{l}\text { Deployment } \\
\text { Focusing }\end{array}$} & $\begin{array}{l}\text { Low Altitude Small UAVs (SUAV) pilot provides a micro-scale mobile communication relay, attempting to } \\
\text { a superior propagation model and increasing bandwidth reuse for emerging traffic hotspots [56]. }\end{array}$ & $\begin{array}{l}\text { - The model achieves an improvement of mean throughput }(>22 \%) \text { and } \mathrm{QOS}(>70 \%) \text { in both rural and } \\
\text { urban environments. } \\
\text {-Offer new possibilities for addressing local traffic imbalances and providing great local coverage. }\end{array}$ \\
\hline & & $\begin{array}{l}\text { Deployment of Drone Small Cells (DSCs), or aerial wireless base station, to optimize the covered area. In the presence of } \\
\text { D2D users, new challenges -as coverage performance- should be tackled [39,42]. }\end{array}$ & $\begin{array}{l}\text { The optimal UAVs' altitude leads to the maximum coverage and system sum-rate simultaneously when } \\
\text { introduces into underlaid D2D communications links. } \\
\text {.I the case of } 2 \text { or more DSCs, an optimal separation distance will grant maximum coverage for a given } \\
\text { target area. }\end{array}$ \\
\hline & \multirow[t]{2}{*}{$\begin{array}{c}\text { Civil } \\
\text { Applications }\end{array}$} & $\begin{array}{l}\text { QoS requirements ranking of UAV networks marked into a practical choice for commercial applications. These aims will outline } \\
\text { the design of emerging aerial networks [37]. }\end{array}$ & $\begin{array}{l}\text { Delimitation of the missions into four categories: Search and Rescue, Coverage Expanding, Delivery/Transport, } \\
\text { Construction. } \\
\text { - SUAVs have turned into handy but inexpensive options for commercial aims due to their their ease } \\
\text { of deployment, low maintenance costs, high-manauverability and ability to hover. } \\
\text {-Wi-fi technology can support several of the prior categories whether each application requires a few number of } \\
\text { hops amongst the nodes. }\end{array}$ \\
\hline & & UAV-aided Wireless Communication may be a promising solution for scenarios without coverage infrastructure [38]. & $\begin{array}{l}\text { UAV systems are more cost-effective than other solutions -such as HAPs and satellites-, providing performance } \\
\text { enhancement and adaptive communications. } \\
\text {-UAV-based networks involve three typical use cases: ubiquitous coverage, relaying, and } \\
\text { information dissemination and data collection. }\end{array}$ \\
\hline
\end{tabular}


Table 5. Phases of UAV-Based Network Models (Continuation)

PHASE APPROACHES
MODELS

ADVANTAGES /
FINDINGS

- The multi-period graph approach derives into Genetic Algorithms. It guarantees the coverage and the efficient management of the UAV consumed energy.

Energy consumption optimization aims to improve the aerial node missions and connectivity in the countryside through a graph-based structure model called RURALPLAN $[59,61,63]$.

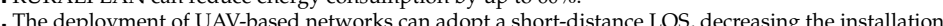

By considering a set of optical fiber links to support the backhaul network, the capital and operation expenditures can be compensated, simplifying the stated model.

- The use of aerial nodes, acting as relays, can cover vast rural extensions, addressing further mobile network generations-such as $5 \mathrm{G}$-to implement steady-links IoT devices,

Novel:
$>2016$

Analysis of joined-architecture networks, mixing UAVs and GEO/LEO satellites, to increase the radiu
and state the usability of aerial nodes to assist fixed-infrastructure networks in the countryside $[58,66]$.

Bearing in mind the optimizing cellular networks aim in the countryside, heritage functionalities

of LTE can achieve prominent coverage radius in the sub- $1 \mathrm{GHz}$ bands, raising the RF propagation on the bedrock of a mixed-architecture network, especially in collect data in the massive MTC

types of application.
- The dependency of the large-scale path loss on the drone's height may be challenging to achieve
significant growth in coverage level boosting the aerial-node perceived interference level significant growth in coverage level, boosting the aerial-node perceived interference level.

LTE networks can provide coverage by UAV nodes in rural areas, chiefly to boost the Command and ince SINR the network diversity, it is possible to improve the network coverage level and The interference conditions-because the drastically-change UAV height-will determine the channel characterization to assess the wireless remote control for the aerial nodes. -Interference canceling and antenna beam selection are strategies to improve the overall-aerial

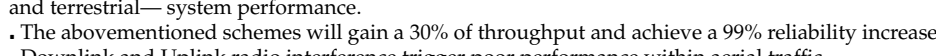

Boosting aerial coverage of rural area network deployment to clear limitations by interference mitigation techniques [54]. Downlink and Uplink radio interference trigger poor performance within aerial traffic. consumed energy minimizing.

A Non-Orthogonal Multiple Access (NOMA) layout for UAV-assisted networks, to provide emergency services in rural areas [67].

. The proposed user-centric strategy follows stochastic geometry approaches for terrestrial users -placed into Voronoi cells- served by UAVs, achieving the location model of both nodes and UEs. .In the case of the NOMA-assisted multi-UAV framework, the analysis of coverage probability can aim to set properly up the network's power allocation factors and targeted rates.
. The correct deployment of MBSs can cover a set of $\mathrm{k}$ nodes with a minimum number of disks of a given circular surface with radius $r$.

Optimization of the UAV-mounted base stations (MBSs) placement, setting forth a Geometric Disk Cover

The computational complexity may be significantly reduced when the coverage starts from

the perimeter of the area boundary. and the PL of the A2G channel will be accurately characterized.

The Path Loss (PL) Characterization for urban, suburban, and rural environments enhances the access technologies for low-altitude aerial networks, considering the UAV height effects on the channel [49,64].

the UAV heights. Albeit it approximates to free-space propagation model at

heights around 100 meters.

- UAV-based networks face a large amount of neighboring interference due to the down-tilted antenna pattern of cellular networks. Besides, the coverage behavior will be affected beneath this scheme. by correctly select the UAV controler and hen perorming network bargaining, he aerial base station could top off a more remarkable improvement on its throughput, SINR per UE capacity in the order of

Improvement of coverage and capacity for future $5 \mathrm{G}$ configuration of aerial networks beneath two algorithm approaches, entropy-based network formation [57] and latency-minimal 3D cell association scheme [51].

With the increase of simultaneous requests within the next-generation heterogeneous wireless network entropy approaches Litting 3 configuration for aerial cellular networks, a yield in reducing up to $46 \%$ in the average total latency would enhance spectral efficiency.

Optimal design of aerial nodes trajectory in cellular-enabled UAV communication with Ground-BS (GBS) trajectory solutions.

Optimal design of aerial nodes trajectory in cellular-enabled UAV comm

Channel's delay-sensitive rates and SNR requirements restrict the target communication performance. UAV's mission completion time may guarantee an efficient method for checking the strategy's feasibility. . In the case of ultra-dense networks, the approach efficiently broad the common issues such as sparse and low-quality coverage and the non-steady aerial links.

Cooperation of small and mini drones can further enhance the performance of the coverage area of FANET - even other aerial-kind networks - by establishing a hierarchical structure of efficient The rapidly unfolding of $\mathrm{UAV}$ carries out in non-dependency of geographical constraints and collaboration of drones $[47,52]$ 
There are other institutions concerned with developing UAS standards, such as GUTMA/GSMA, ASTM International, IEEE, ISO, EUROCAE, IETF, and JARUS [101]. For a handy insight of the network safety, by avoiding a loss of service due to their proximity, we have briefly recapped the 3GPP suggested edges [99] in the Listing 1, as long as new releases will emerge in enhanced-supporting of the LTE aim [70].

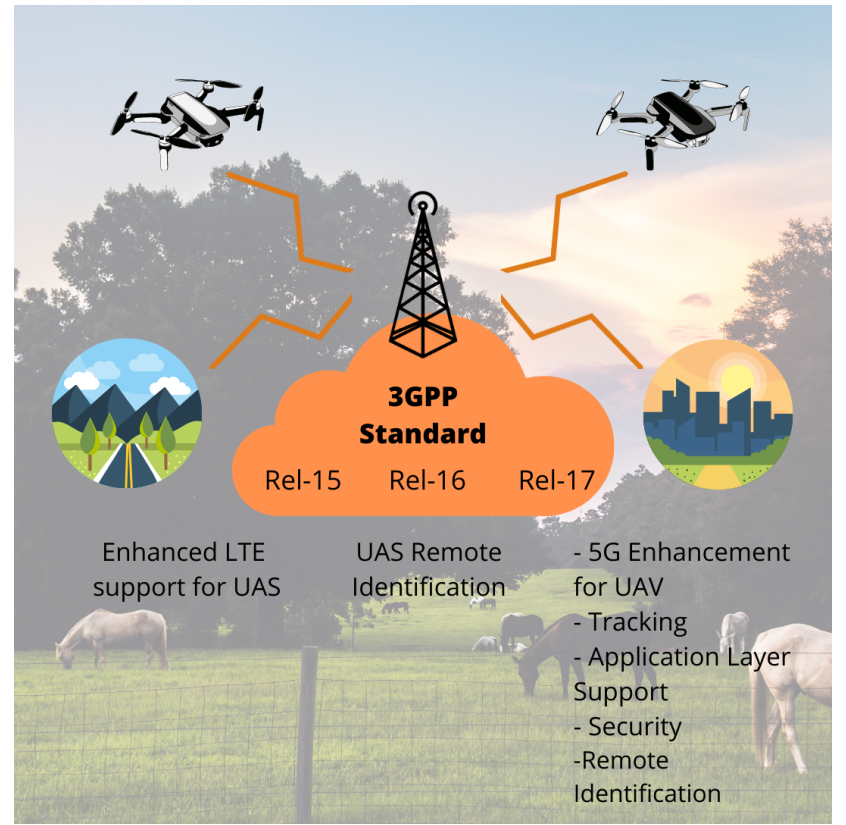

Figure 6. UAS Addressing in 3GPP Standards
Listing 1. 3GPP's Releases Outline involved in UAS Communications

- Release 15 addressed the research studies about the ability for UAVs to be served using LTE networks, besides a comprehensive analysis of potential interferences between $\mathrm{eN}$ odeB and UAS.

- Release 16 has an overview of the potential requirements and use cases to enable the necessary connectivity between UAS and UTM.

- $\quad$ Release 17 approaches the use cases and requirements for UAS identification and tracking beneath the application layer. It also gathers the $5 \mathrm{G}$ connectivity needs of drones in new KPIs into a 3GPP subscription.

\subsection{Other Engaging Solutions}

We have thoroughly reviewed the implication to assist rural networks by employing UAVs; besides, other engaging solutions can enable broad coverage in the countryside to shed light on its connectivity. On the 2000s' onset, SCPs appeared to be a prominent answer for fixed and mobile applications. These devices remarkably outpaced the unprofitable gap since they have arisen as a cost-effective solution for urban, suburban, and rural areas [18].

Aside from dedicated area coverage independence, authors in [18] pointed out that Sky Station platforms may provide higher capacity-by higher frequency reuse-than other wireless systems, the possibility of grant enhanced roaming, as well as choosing their stationary point. Another seamless option for rural connectivity has been the satellites, namely LEO configuration. The following sub-subsections will deepen the strategies mentioned earlier, whereas the UAVs also fall into this category.

\subsubsection{Altitude Platforms}

The altitude platforms are grouped into LAPs (Low-altitude platforms) and HAPs (High-altitude platforms). Song et al. in [12], granted the main difference about the prior categories. LAPs gather the aerial platforms at an altitude down of $20 \mathrm{~km}$. UAVs, drones, and blimps fall into this group since they cannot support higher payload capacities, and their autonomy relies on SWAP constraints [13]. As Subsection 3.1 in-depth met, UAVs can perform far-flung coverage, increase the redundancy, and increase survivability, leveraging the swarm FANET architecture [12].

LAPs have lent dynamic and scalable networks which can quickly cover broader regions, although there are by-payload stuck. In this case, there are two ways to limit: First, developing a suitable propagation model that includes the elevation angle-deployed at 
several altitudes - along with the MIMO output antenna diversity gain, especially for the last mile connectivity [16]. In the UAV case, the strategy may contain a formulation of statistical assessment of A2G propagation by either using Ray Launching or Ray Tracing geometrical optics models [14]. Second, Drone-to-Drone communication arises as reliable collision avoidance system [13].

On the other hand, HAPs operate in a quasi-stationary position at an altitude of 20 to $50 \mathrm{~km}$, becoming a viable option to furnish capacity and coverage enhancement [12]. Authors in [11] have envisioned these platforms as a super macro BS (HAPs-SMBS) to unfold high-traffic-volume networks in a metropolitan area to bargaining with the smart city paradigms. Facing the LEO constellation shortcomings, HAPs-SMBS can mask the high path loss and the high mobility effects.

The potential uses of HAPs - to tackle the rural not-spots - shed light on dynamically manage radio resources and mitigate the crossed interference [15]. The rural environment has admitted more prevalence to network coverage instead of higher capacity density. The reason why HAPS needs a lower investment and providing high quality - even providing higher terrestrial QoS — has carried out this alternative to cover rural and remote areas [17]. At this point, likely exploitation of radio environment maps and artificial intelligence on the ongoing infrastructure may allow a radius coverage area of more than $30 \mathrm{~km}$, as Chukwuebuka highlighted in [17].

\subsubsection{Satellites}

Satellite-based architecture has furnished an outstanding architecture to hook up the highly dispersed and remote rural nodes due to their scalability and flexibility to reach vast geographical areas. In function of the developed network scope, the satellites' orbit unleashes a defined classification [22]: LEO (altitude between $500 \mathrm{~km}$ and 2000 $\mathrm{km}$ ), MEO (altitude into the range 5000 and $20000 \mathrm{~km}$ ), GEO (altitude of $35800 \mathrm{~km}$ ).

Underneath the condition of service-as-primary-resource, LEO architecture, on the one hand, solve the latency issues; on the other hand, it has added remarkable bit rate capacity by multi-beam technology [19]. In contrast, e.g., GEO holds limited these parameters. Heading to the best alternative for rural not-spots, LEO has become the best complementary structure of terrestrial networks in the countryside, figuring out several shouldered challenges, such as routing problems and raining attenuation [21].

To provide seamless and continuous service by LEO satellite networks, these have adopted constellation shape whereas QoS is guaranteed, fueled by novel routing protocols regarding UE location and exploiting the deterministic LEO topology. Therefore, the route bottlenecks should be foreseen in any pair of end-users, as the authors said in [20]. By avoiding the design planning deficiencies, the greater system's user capacity, the larger the covered geographical zone [21].

\section{Discussion}

At this height, the rural zones have struggled to embrace fully-fledged connectivity. Regarding Latin America's situation, three considerable constraints are jamming with the ubiquitous rural coverage aim: First, the MNOs do not furnish a suitable telecom infrastructure outside of urban environments. Secondly, the rural settlements are concentrated but geographically sparse, occupying common hot spots. Finally, the studied strategies should be based on bespoke hardware requirements since the uneven relief and ecosystem variation hamper with a static estimation of channel parameters-the last demand higher investment cost—which seems unprofitable for ISPs and MNOs.

The not-spots affects directly rural inhabitants, especially those who attempt to foster rural businesses, mainly agricultural and new industrial activities in the countryside. Hence, Table 6 states the advantages and shortcomings of the studies solutions-in Section 3-while we spur for ongoing research of UAV-assisted networks deployment driven by mobility, cost-effective, and the other leverages outlined in Table 6, that can bring over the uncovered regions. Further works include analysis of dynamical prop- 
agation model and simulations of LTE-aiming for 5G-NR deployment-at incoming experimental stages.

Table 6. Comparison Among the Analyzed Solutions for Rural Coverage

\begin{tabular}{|c|c|c|}
\hline Solution [Section] & Advantages & Disadvantages \\
\hline UAVs [3.1] & $\begin{array}{l}\text { - Easily deployable and portable. } \\
\text { - Reliable infrastructure to enhance } \\
\text { coverage. } \\
\text { - New security standards by new routing } \\
\text { protocols. } \\
\text { - Compatible with others as terrestrial as } \\
\text { aerial network's platforms. }\end{array}$ & $\begin{array}{l}\text { - Static-channel-modeling intermittent } \\
\text { connectivity. } \\
\text { - Energy constraints and limited effective } \\
\text { payload. } \\
\text { - Uncertainty on legislative. } \\
\text { - Inefficient obstacle aware rollout. }\end{array}$ \\
\hline APs [3.2] & $\begin{array}{l}\text { - Commit to cover immense inaccessible } \\
\text { areas. } \\
\text { - Allows adaptable resource allocation. } \\
\text { - Low roll-out costs. } \\
\text { - Guarantee connectivity by a single } \\
\text { platform. } \\
\text { - Agile deployment. } \\
\text { - Payload upgrading. }\end{array}$ & $\begin{array}{l}\text { - Few protocols standardization. } \\
\text { - Unfit design of traffic aggregation. } \\
\text { - Poor raters of interference mitigation in } \\
\text { shared spectrum. }\end{array}$ \\
\hline LEOs [3.2] & $\begin{array}{l}\text { - Enable higher QoS than terrestrial. } \\
\text { - Reach a latency issues standard. } \\
\text { - Add significant bit rate capacity. } \\
\text { - Provide high capacity backhaul. }\end{array}$ & $\begin{array}{l}\text { - Insufficient coverage time assessment. } \\
\text { - Higher cost of deployment and } \\
\text { maintenance. } \\
\text { - Most affected by fading effects. } \\
\text { - Unreliable communication at low } \\
\text { elevation angles. }\end{array}$ \\
\hline
\end{tabular}

\subsection{Future Research Opportunities}

In the prior section, we have introduced three achievable solutions to strive against the countryside's not-spots. There remain shortcomings stuck in the fully-fledged way of granting connectivity to pursue endurance in the deployed system. UAV-based networks seem to be an attractive option due to their commercial affordability, as we pointed out in Subsection 3.1. However, for now, both UAS and Altitude Platforms have factors opposed to the large scale use, such as payload capability-to shoulder the network equipment-and the non-enough MNO interest, behind higher returning investment rates.

Consequently, three categories claim for further analysis in the case of deploying aerial networks. Firstly, channel modeling needs to be supplied by a realistic propagation model since most are still limited to a single device or focus on particular environments. Also, there is a considerable need to characterize the by-mobility Doppler effect, besides the channel's captured time variation addresses more precision and accuracy.

Secondly, aerial platforms lack an optimal 3D placement. A matchless location bestows the coexistence with the terrestrial cellular networks and avoids mutual interference with GBS. In the case of UAS, an optimal arrangement of UAV-BS can yield a minimum downlink transmission latency, setting previously up the drone-BS location and the transmission bandwidth [43]. This approach can reduce the total flight time, also enhancing energy consumption.

Concern to the energy issues of SCP — which may be the foremost challenge to assure connectivity's significant periods - there has been investigated the utilization of peer-topeer energy sharing since energy is a limited resource in mobile networks because they are jammed yet in non-renewable sources like batteries. According to the application, an attractive solution to outpace the excessive consumption of energy, mainly focused on renewable sources, appears to be a significant research field to guarantee communication availability [97]. 
Thirdly, an outstanding cellular network planning foresees the minimum number of required aerial nodes to cover a given geographical area, either partially connected or entirely disconnected. Hence, to maximize the total covered zones, there should be a previous identification of users and obstacles. Underneath this regard, prior frequency planning and signaling overhead analysis can assure a greater network throughput, especially for high-frequency bands.

Finally, an in-depth design of the bespoke-solution construction affords countless advantages to aim for the fully connected countryside. In this case, embracing an expected radius of $30 \mathrm{~km} \mathrm{[15]} \mathrm{—or} \mathrm{even} \mathrm{more} \mathrm{significant} \mathrm{value-assures} \mathrm{the} \mathrm{coexistence}$ of either LAPs or HAPs with terrestrial systems, sharing the same spectrum can extend the coverage in rural and remote areas. Other strategies involve a novel antenna array design and aerial swarms or constellations, which are expected to be further research in broader $5 \mathrm{G}$ investigations.

\section{Conclusions}

Nowadays, complete Internet access to rural zones may be a paradoxical reality due to the lack of efforts to deploy a suitable mobile networks infrastructure. However, data demand has grown recently since many rural inhabitants consider using technology to improve their quality of life by implementing trending technologies, such as IoT. Although Latin American countries have recently envisaged closing the connectivity gap, there are remote geographical zones where the not-spots are a significant challenge to governments because they strive to outpace inequality under the insight of fullyfledged coverage.

Bearing in mind our study cases, Mexico and Colombia, which have economically and technologically developed in the last decade, the connectivity gaps are noticeable yet. Therefore, implementing alternative and efficient solutions-as listed in Section 3approach hooking the peripheral population up by a reliable deployment. The COVID-19 pandemic has accelerated the reshaping of a noteworthy need for connectivity since most of our performed activities leverage digitalization growth to attempt affordability and readily access. Although several rural populations remain fully offline, the recent efforts to stimulate new steady links have triggered new opportunities to access online education, employment, or critical health and sanitation advice.

We have summarized some strategies to strengthen connectivity in rural environments, especially for Latin American countries. By establishing statistics that best drawn the mentioned panorama, we encourage further access to ICT and lay on the target of providing affordable access to the Internet in developed countries, which in turn considers rural and geographically remote populations. Hence, solutions such as UAVs, HAPs / LAPs, and LEO satellites have arisen for the most cost-effective bargaining. However, we have comprehensively studied UAS scope in communication because its efficient maneuverability can aboard the coverage problem through a solid construction of either GBS or FANET approaches.

Author Contributions: All authors have read and agreed to the published version of the manuscript.

Funding: This research received no external funding.

Institutional Review Board Statement: Not applicable.

Informed Consent Statement: Not applicable.

Acknowledgments: Cabrera-Castellanos would like to acknowledge to the Consejo Nacional de Ciencia y Tecnología (CONACyT) because this work has been partially supported by the National scholarship with id. 1013611.

Conflicts of Interest: The authors declare no conflict of interest. The funders had no role in the design of the study; in the collection, analyses, or interpretation of data; in the writing of the manuscript, or in the decision to publish the results. 


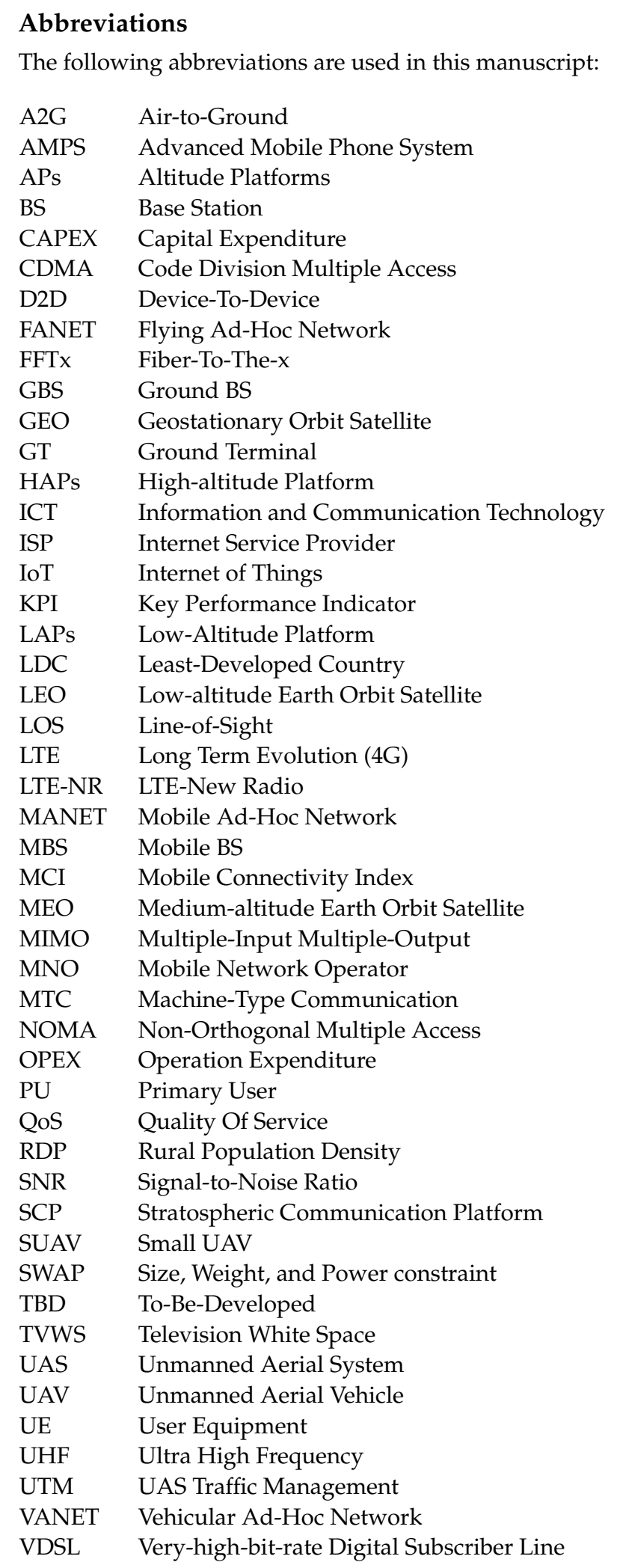

\section{References}

1. Kim, H.; Kim, Y.; Park, P.; Ahn, S.; Jo, J.; Park, S.; Park, C. Network coverage expansion in radio access network sharing. 2017 Sixth International Conference on Future Generation Communication Technologies (FGCT), 2017, pp. 1-5. doi:10.1109/FGCT.2017.8103393.

2. Paliwal, K.K.; Singh, S.; Bajaj, S. Rural communication enhancement using mobile ad-hoc network. 2017 7th International Conference on Cloud Computing, Data Science Engineering - Confluence, 2017, pp. 387-391. doi:10.1109/CONFLUENCE.2017.7943180. 
3. Office of Communications of United Kingdom. Connected Nations Report 2016. Technical report, OfCom, 2016.

4. Kalvin Bahia, A.D. The State of Mobile Internet Connectivity 2020. Technical report, GSMA Intelligence, 2020.

5. Secretary-General. Progress towards the Sustainable Development Goals. Technical report, United Nations, 2020.

6. Nations, U. Goal 9: Build resilient infrastructure, promote sustainable industrialization and foster innovation. www.un.org/ sustainabledevelopment/infrastructure-industrialization/, 2019.

7. Intelligence, G. GSMA Mobile Connectivity Index. www.mobileconnectivityindex.com, 2019.

8. Kelif, J. Coverage and Performance of Stratospheric Balloons Wireless Networks. 2016 IEEE 27th Annual International Symposium on Personal, Indoor, and Mobile Radio Communications (PIMRC), 2016, pp. 1-6. doi:10.1109/PIMRC.2016.7794908.

9. Loon LLC. The Loon Project. www.loon.com/, 2020.

10. Seyedi, Y.; Safavi, S.M. On the Analysis of Random Coverage Time in Mobile LEO Satellite Communications. IEEE Communications Letters 2012, 16, 612-615. doi:10.1109/LCOMM.2012.031912.112323.

11. Alam, M.S.; Kurt, G.K.; Yanikomeroglu, H.; Zhu, P.; Đào, N.D. High Altitude Platform Station Based Super Macro Base Station Constellations. IEEE Communications Magazine 2021, 59, 103-109. doi:10.1109/MCOM.001.2000542.

12. Song, S.; Choi, M.; Goh, Y.; Yun, J.; Yoo, W.; Yang, W.; Jung, J.; Chung, J. Analysis of wireless backhaul networks based on aerial platform technology for 6G systems. Computers, Materials and Continua 2020. doi:10.32604/cmc.2020.09052.

13. Becker, D.; Fiebig, U.; Schalk, L. Wideband Channel Measurements and First Findings for Low Altitude Drone-to-Drone Links in an Urban Scenario. 2020 14th European Conference on Antennas and Propagation (EuCAP), 2020.

14. Arpaio, M.J.; Vitucci, E.M.; Barbiroli, M.; Degli-Esposti, V.; Masotti, D.; Fuschini, F. Narrowband Characteristics of Air-to-Ground Propagation for UAV Assisted Networks in Urban Environments By Means of Fast Ray-Launching Simulations. 2020 IEEE 91st Vehicular Technology Conference (VTC2020-Spring), 2020.

15. Arum, S.C.; Grace, D.; Mitchell, P.D. A review of wireless communication using high-altitude platforms for extended coverage and capacity. Computer Communications 2020, 157, 232-256. doi:https://doi.org/10.1016/j.comcom.2020.04.020.

16. Almalki, F.A.; Angelides, M.C. A machine learning approach to evolving an optimal propagation model for last mile connectivity using low altitude platforms. Computer Communications 2019, 142-143, 9-33. doi:https://doi.org/10.1016/j.comcom.2019.04.001.

17. Setiawan, E. The Potential Use of High Altitude Platform Station in Rural Telecommunication Infrastructure. 2018 International Conference on ICT for Rural Development (IC-ICTRuDev), 2018. doi:10.1109/ICICTR.2018.8706563.

18. Ilcev, S.D.; Singh, A. Development of stratospheric communication platforms (SCP) for rural applications. 2004 IEEE Africon. 7th Africon Conference in Africa (IEEE Cat. No.04CH37590), 2004. doi:10.1109/AFRICON.2004.1406665.

19. Araujo, M.; Ekenberg, L.; Confraria, J. Satellite backhaul for macro-cells, as an alternative to optical fibre, to close the digital divide. IEEE Wireless Communications and Networking Conference, WCNC, 2019, Vol. 2019-April.

20. Özgür Erçetin.; Krishnamurthy, S.; Dao, S.; Tassiulas, L. Provision of guaranteed services in broadband LEO satellite networks. Computer Networks 2002. doi:https:/ /doi.org/10.1016/S1389-1286(01)00298-5.

21. Arifin, M.A.; Khamsah, N.M.N. A Case Study in User Capacity Planning for Low Earth Orbit Communication Satellite. ICARES 2018 - Proceedings of the 2018 IEEE International Conference on Aerospace Electronics and Remote Sensing Technology, 2018.

22. Vatalaro, F.; Corazza, G.E.; Caini, C.; Ferrarelli, C. Analysis of LEO, MEO, and GEO global mobile satellite systems in the presence of interference and fading. IEEE Journal on selected areas in communications 1995, 13, 291-300.

23. Dovis, F.; Sellone, F. Increasing the capacity of existing terrestrial outdoor radio mobile systems by means of UAV-HALE platforms. IEEE Vehicular Technology Conference, 2000, Vol. 3, pp. 2365-2369.

24. Niessen, C.W. Battlefield connectivity via airborne communications nodes. Proceedings of SPIE - The International Society for Optical Engineering, 1997, Vol. 3080, pp. 72-78.

25. Han, Z.; Swindlehurst, A.L.; Liu, K.J.R. Optimization of MANET connectivity via smart deployment/movement of unmanned air vehicles. IEEE Transactions on Vehicular Technology 2009, 58, 3533-3546.

26. Basu, P.; Redi, J.; Shurbanov, V. Coordinated flocking of UAVS for improved connectivity of mobile ground nodes. Proceedings IEEE Military Communications Conference MILCOM, 2004, Vol. 3, pp. 1628-1634.

27. Han, Z.; Swindlehurst, A.L.; Liu, K.J.R. Smart deployment/movement of unmanned air vehicle to improve connectivity in MANET. IEEE Wireless Communications and Networking Conference, WCNC, 2006, Vol. 1, pp. 252-257.

28. Saad, W.; Han, Z.; Başar, T.; Debbah, M.; Hjørungnes, A. A selfish approach to coalition formation among unmanned air vehicles in wireless networks. Proceedings of the 2009 International Conference on Game Theory for Networks, GameNets '09, 2009, pp. 259-267.

29. Goddemeier, N.; Daniel, K.; Wietfeld, C. Coverage evaluation of wireless networks for unmanned aerial systems. 2010 IEEE Globecom Workshops, GC'10, 2010, pp. 1760-1765.

30. Hyland, M.T.; Mullins, B.E.; Baldwin, R.O.; Temple, M.A. Simulation-based performance evaluation of mobile ad hoc routing protocols in a swarm of unmanned aerial vehicles. Proceedings - 21st International Conference on Advanced Information Networking and Applications Workshops/Symposia, AINAW'07, 2007, Vol. 1, pp. 249-256.

31. Chandrashekar, K.; Dekhordi, M.R.; Baras, J.S. Providing full connectivity in large ad-hoc networks by dynamic placement of aerial platforms. Proceedings - IEEE Military Communications Conference MILCOM, 2004, Vol. 3, pp. 1429-1436.

32. Cerasoli, C. An analysis of unmanned airborne vehicle relay coverage in urban environments. Proceedings - IEEE Military Communications Conference MILCOM, 2007. 
33. Palazzi, C.E.; Roseti, C.; Luglio, M.; Gerla, M.; Sanadidi, M.Y.; Stepanek, J. Satellite coverage in urban areas using unmanned airborne vehicles (UAVs). 2004 IEEE 59th Vehicular Technology Conference. VTC 2004-Spring (IEEE Cat. No.04CH37514), 2004, Vol. 5, pp. 2886-2890 Vol.5.

34. Brown, T.; Argrow, B.; Frew, E.; Dixon, C.; Henkel, D.; Elston, J.; Gates, H., Experiments using small unmanned aircraft to augment a mobile ad hoc network; 2007; Vol. 9780521895842, Emerging Technologies in Wireless LANs: Theory, Design, and Deployment, pp. 695-718.

35. Huo, J.; Xu, Z.; Zhang, Y.; Shan, X. A UAV mobile strategy in mobile ad hoc networks. 2011 International Conference on Electronics, Communications and Control, ICECC 2011 - Proceedings, 2011, pp. 686-690.

36. Palazzi, C.E.; Roseti, C.; Luglio, M.; Gerla, M.; Sanadidi, M.Y.; Stepanek, J. Enhancing transport layer capability in HAPS-satellite integrated architecture. Wireless Personal Communications 2005, 32, 339-356.

37. Hayat, S.; Yanmaz, E.; Muzaffar, R. Survey on Unmanned Aerial Vehicle Networks for Civil Applications: A Communications Viewpoint. IEEE Communications Surveys and Tutorials 2016, 18, 2624-2661.

38. Zeng, Y.; Zhang, R.; Lim, T.J. Wireless communications with unmanned aerial vehicles: Opportunities and challenges. IEEE Communications Magazine 2016, 54, 36-42.

39. Mozaffari, M.; Saad, W.; Bennis, M.; Debbah, M. Unmanned Aerial Vehicle with Underlaid Device-to-Device Communications: Performance and Tradeoffs. IEEE Transactions on Wireless Communications 2016, 15, 3949-3963.

40. Mozaffari, M.; Saad, W.; Bennis, M.; Debbah, M. Efficient Deployment of Multiple Unmanned Aerial Vehicles for Optimal Wireless Coverage. IEEE Communications Letters 2016, 20, 1647-1650.

41. Lyu, J.; Zeng, Y.; Zhang, R.; Lim, T.J. Placement Optimization of UAV-Mounted Mobile Base Stations. IEEE Communications Letters 2017, 21, 604-607.

42. Mozaffari, M.; Saad, W.; Bennis, M.; Debbah, M. Drone small cells in the clouds: design, deployment and performance analysis 2015 IEEE Global Communications Conference, GLOBECOM 2015, 2015.

43. Mozaffari, M.; Saad, W.; Bennis, M.; Nam, Y..; Debbah, M. A Tutorial on UAVs for Wireless Networks: Applications, Challenges, and Open Problems. IEEE Communications Surveys and Tutorials 2019, 21, 2334-2360.

44. Sahingoz, O.K. Networking models in flying Ad-hoc networks (FANETs): Concepts and challenges. Journal of Intelligent and Robotic Systems: Theory and Applications 2014, 74, 513-527.

45. Sharma, V.; Bennis, M.; Kumar, R. UAV-Assisted Heterogeneous Networks for Capacity Enhancement. IEEE Communications Letters 2016, 20, 1207-1210.

46. Li, B.; Fei, Z.; Zhang, Y. UAV communications for $5 \mathrm{G}$ and beyond: Recent advances and future trends. IEEE Internet of Things Journal 2019, 6, 2241-2263.

47. Wang, J.; Jiang, C.; Han, Z.; Ren, Y.; Maunder, R.G.; Hanzo, L. Taking Drones to the Next Level: Cooperative Distributed Unmanned-Aerial-Vehicular Networks for Small and Mini Drones. IEEE Vehicular Technology Magazine 2017, $12,73-82$.

48. Fotouhi, A.; Qiang, H.; Ding, M.; Hassan, M.; Giordano, L.G.; Garcia-Rodriguez, A.; Yuan, J. Survey on UAV Cellular Communications: Practical Aspects, Standardization Advancements, Regulation, and Security Challenges. IEEE Communications Surveys and Tutorials 2019, 21, 3417-3442.

49. Al-Hourani, A.; Gomez, K. Modeling Cellular-to-UAV Path-Loss for Suburban Environments. IEEE Wireless Communications Letters 2018, 7, 82-85.

50. Zhang, S.; Zeng, Y.; Zhang, R. Cellular-enabled UAV communication: A connectivity-constrained trajectory optimization perspective. IEEE Transactions on Communications 2019, 67, 2580-2604.

51. Mozaffari, M.; Kasgari, A.T.Z.; Saad, W.; Bennis, M.; Debbah, M. Beyond 5G with UAVs: Foundations of a 3D Wireless Cellular Network. IEEE Transactions on Wireless Communications 2019, 18, 357-372.

52. Wang, H.; Ding, G.; Gao, F.; Chen, J.; Wang, J.; Wang, L. Power Control in UAV-Supported Ultra Dense Networks: Communications, Caching, and Energy Transfer. IEEE Communications Magazine 2018, 56, 28-34.

53. Yanmaz, E. Connectivity versus area coverage in unmanned aerial vehicle networks. IEEE International Conference on Communications, 2012, pp. 719-723.

54. Nguyen, H.C.; Amorim, R.; Wigard, J.; Kovacs, I.Z.; Sorensen, T.B.; Mogensen, P.E. How to Ensure Reliable Connectivity for Aerial Vehicles over Cellular Networks. IEEE Access 2018, 6, 12304-12317.

55. Sahingoz, O.K. Mobile networking with UAVs: Opportunities and challenges. 2013 International Conference on Unmanned Aircraft Systems, ICUAS 2013 - Conference Proceedings, 2013, pp. 933-941.

56. Guo, W.; Devine, C.; Wang, S. Performance analysis of micro unmanned airborne communication relays for cellular networks. 2014 9th International Symposium on Communication Systems, Networks and Digital Signal Processing, CSNDSP 2014, 2014, pp. 658-663.

57. Sharma, V.; Srinivasan, K.; Chao, H..; Hua, K..; Cheng, W.. Intelligent deployment of UAVs in 5G heterogeneous communication environment for improved coverage. Journal of Network and Computer Applications 2017, 85, 94-105.

58. Carrillo, D.; Seki, J. Rural area deployment of internet of things connectivity: LTE and LoRaWAN case study. Proceedings of the 2017 IEEE 24th International Congress on Electronics, Electrical Engineering and Computing, INTERCON $2017,2017$.

59. Jimenez, J.G.; Chiaraviglio, L.; Amorosi, L.; Blefari-Melazzi, N. Multi-Period Mission Planning of UAVs for 5G Coverage in Rural Areas: A Heuristic Approach. Proceedings of the 2018 9th International Conference on the Network of the Future, NOF 2018, 2018, pp. 52-59. 
60. Chen, Y.; Zhang, H.; Xu, M. The coverage problem in UAV network: A survey. 5th International Conference on Computing Communication and Networking Technologies, ICCCNT 2014, 2014.

61. Chiaraviglio, L.; Amorosi, L.; Blefari-Melazzi, N.; Dell'olmo, P.; Lo Mastro, A.; Natalino, C.; Monti, P. Minimum Cost Design of Cellular Networks in Rural Areas with UAVs, Optical Rings, Solar Panels, and Batteries. IEEE Transactions on Green Communications and Networking 2019, 3, 901-918.

62. Kovács, I.Z.; Amorim, R.; Nguyen, H.C.; Wigard, J.; Mogensen, P. Interference analysis for UAV connectivity over LTE using aerial radio measurements. IEEE Vehicular Technology Conference, 2018, Vol. 2017-September, pp. 1-6.

63. Amorosi, L.; Chiaraviglio, L.; D’Andreagiovanni, F.; Blefari-Melazzi, N. Energy-efficient mission planning of UAVs for 5G coverage in rural zones. 2018 IEEE International Conference on Environmental Engineering, EE 2018 - Proceedings, 2018.

64. Wang, K.; Zhang, R.; Wu, L.; Zhong, Z.; He, L.; Liu, J.; Pang, X. Path loss measurement and modeling for low-altitude UAV access channels. IEEE Vehicular Technology Conference, 2018, Vol. 2017-September.

65. Nguyen, H.C.; Amorim, R.; Wigard, J.; Kovács, I.Z.; Mogensen, P. Using LTE networks for UAV command and control link: A rural-area coverage analysis. IEEE Vehicular Technology Conference, 2018, Vol. 2017-September, pp. 1-6.

66. Giambene, G.; Addo, E.O.; Kota, S. 5G aerial component for IoT support in remote rural areas. IEEE 5G World Forum, 5GWF 2019 - Conference Proceedings, 2019, pp. 572-577.

67. Hou, T.; Liu, Y.; Sun, X.; Song, Z.; Chen, Y. Non-orthogonal multiple access in multi-UAV networks. IEEE Vehicular Technology Conference, 2019, Vol. 2019-September.

68. Shakhatreh, H.; Sawalmeh, A.H.; Al-Fuqaha, A.; Dou, Z.; Almaita, E.; Khalil, I.; Othman, N.S.; Khreishah, A.; Guizani, M. Unmanned Aerial Vehicles (UAVs): A Survey on Civil Applications and Key Research Challenges. IEEE Access 2019, 7, 4857248634.

69. Khawaja, W.; Guvenc, I.; Matolak, D.W.; Fiebig, U.; Schneckenburger, N. A Survey of Air-to-Ground Propagation Channel Modeling for Unmanned Aerial Vehicles. IEEE Communications Surveys Tutorials 2019, 21, 2361-2391. doi:10.1109/COMST.2019.2915069.

70. Muruganathan, S.D.; Lin, X.; Maattanen, H.L.; Sedin, J.; Zou, Z.; Hapsari, W.A.; Yasukawa, S. An Overview of 3GPP Release-15 Study on Enhanced LTE Support for Connected Drones, 2019.

71. Jiménez, J.G.; Chiaraviglio, L.; Amorosi, L.; Blefari-Melazzi, N. Multi-Period Mission Planning of UAVs for 5G Coverage in Rural Areas: a Heuristic Approach. 2018 9th International Conference on the Network of the Future (NOF), 2018, pp. 52-59. doi:10.1109/NOF.2018.8598123.

72. Gatwaza, W.W.; Afullo, T.J.; Sewsunker, R. Characterization of rural traffic and evaluation of cellular protocols for fixed-mobile rural application. 2004 IEEE Africon. 7th Africon Conference in Africa (IEEE Cat. No.04CH37590), 2004, Vol. 1, pp. 245-250 Vol.1 doi:10.1109/AFRICON.2004.1406667.

73. Tang, Y.F.; Zhang, Y.X.; Kan, S.L. Indoor RF signal coverage solution. 2017 IEEE Asia Pacific Microwave Conference (APMC), 2017, pp. 233-236. doi:10.1109/ APMC.2017.8251421.

74. Chen, J. Network Analysis Based on 2/4G Common Coverage Research in Rural Area. 2018 IEEE International Conference on Internet of Things (iThings) and IEEE Green Computing and Communications (GreenCom) and IEEE Cyber, Physical and Social Computing (CPSCom) and IEEE Smart Data (SmartData), 2018, pp. 295-300.

75. Ding, Y.; Liu, H.; Cao, X. An Intelligent Computation of Coverage and Capacity of Base Station in 3G Mobile Communications Network. 2008 International Conference on Computational Intelligence and Security, 2008, Vol. 2, pp. $494-497$.

76. Ganesh, R.; Ning Yang.; Regitz, S.; Giordano, A.; Fye, D. Coverage considerations for CDMA overlay of rural analog sites. 2000 IEEE International Conference on Personal Wireless Communications. Conference Proceedings (Cat. No.00TH8488), 2000, pp. 288-292. doi:10.1109/ICPWC.2000.905821.

77. Manna, G.C.; Jharia, B. Mobile WiMAX coverage evaluation for rural areas of India. 13th International Conference on Advanced Communication Technology (ICACT2011), 2011, pp. 942-947.

78. Amine, L.M.; Adil, E.B.; Aawatif, P.H. Toward enhancing connectivity through TVWS in outdoor rural isolated environment. 2017 Sensors Networks Smart and Emerging Technologies (SENSET), 2017, pp. 1-4. doi:10.1109/SENSET.2017.8125069.

79. Araújo, M.; Ekenberg, L.; Confraria, J. Rural networks cost comparison between 5G (mobile) and FTTx (fixed) scenarios. 2018 IEEE 29th Annual International Symposium on Personal, Indoor and Mobile Radio Communications (PIMRC), 2018 , pp. 259-264. doi:10.1109/PIMRC.2018.8580981.

80. Rendon Schneir, J.; Xiong, Y. A cost study of fixed broadband access networks for rural areas. Telecommunications Policy 2016, 40, 755-773. Technological change and the provision, consumption and regulation of services: Papers from a European ITS regional conference, doi:https://doi.org/10.1016/j.telpol.2016.04.002.

81. Smirnov, N.I.; Eremichev, V.I.; Tsyrenova, L.A. Increase in the efficiency of the coverage area in the cellular communication systems. 2017 Systems of Signal Synchronization, Generating and Processing in Telecommunications (SINKHROINFO), 2017, pp. 1-4. doi:10.1109/SINKHROINFO.2017.7997558.

82. Prieger, J.E. The broadband digital divide and the economic benefits of mobile broadband for rural areas. Telecommunications Policy 2013, 37, 483-502.

83. Huang, L.; Zhou, Y.; Wang, Y.; Han, X.; Shi, J.; Chen, X. Advanced coverage optimization techniques for small cell clusters. China Communications 2015, 12, 111-122. doi:10.1109/CC.2015.7224694.

84. Ilcev, S.D.; Singh, A. Development of stratospheric communication platforms (SCP) for rural applications. 2004 IEEE Africon. 7th Africon Conference in Africa (IEEE Cat. No.04CH37590), 2004, Vol. 1, pp. 233-238 Vol.1. doi:10.1109/AFRICON.2004.1406665. 
85. Mucalo, A.K.; Simac, G.; Tekovic, A. Criteria for mobile coverage obligations - Overview in Europe. 2015 57th International Symposium ELMAR (ELMAR), 2015, pp. 181-184. doi:10.1109/ELMAR.2015.7334525.

86. Rudd, R.F. Indoor coverage considerations for high-elevation angle systems. Second International Conference on $3 \mathrm{G}$ Mobile Communication Technologies, 2001, pp. 171-174. doi:10.1049/cp:20010035.

87. Akpakwu, G.A.; Silva, B.J.; Hancke, G.P.; Abu-Mahfouz, A.M. A Survey on 5G Networks for the Internet of Things: Communication Technologies and Challenges. IEEE Access 2017, 6.

88. Naddafzadeh-Shirazi, G.; Lampe, L.; Vos, G.; Bennett, S. Coverage enhancement techniques for machine-to-machine communications over LTE. IEEE Communications Magazine 2015, 53.

89. Yazdani, O.; MirJalili, G. A survey of distributed resource allocation for device-to-device communication in cellular networks. 19th CSI International Symposium on Artificial Intelligence and Signal Processing, AISP 2017, 2018, Vol. 2018-January.

90. Ioannou, N.; Katsianis, D.; Varoutas, D. Comparative techno-economic evaluation of LTE fixed wireless access, FTTdp G.fast and FTTC VDSL network deployment for providing 30Mbps broadband services in rural areas. Telecommunications Policy $2020,44$. doi:https://doi.org/10.1016/j.telpol.2019.101875.

91. Yilmaz, O.N.C.; Teyeb, O.; Orsino, A. Overview of LTE-NR Dual Connectivity. IEEE Communications Magazine $2019,57$.

92. Sundquist, M.; Markendahl, J. A case study cost modelling of regulatory alternatives to mitigate the mobile network coverage and capacity problems in rural areas; International Telecommunications Society (ITS): Calgary, 2015; 26th European Regional Conference of the International Telecommunications Society (ITS): "What Next for European Telecommunications?", Madrid, Spain, 24th-27th June, 2015.

93. Villapol, M.E.; Liu, W.; Gutierrez, J.; Qadir, J.; Gordon, S.; Tan, J.; Chiaraviglio, L.; Wu, J.; Zhang, W. A Sustainable Connectivity Model of the Internet Access Technologies in Rural and Low-Income Areas. Smart Grid and Innovative Frontiers in Telecommunications; Chong, P.H.J.; Seet, B.C.; Chai, M.; Rehman, S.U., Eds.; Springer International Publishing: Cham, 2018; pp. 93-102.

94. Handforth, C. Closing the Coverage Gap: How Innovation Can Drive Rural Connectivity. Technical report, GSMA Association, 2019.

95. Cruz, G.; Touchard, G.; Buckwell, M.; Liberatore, F. Enabling Rural Coverage: Regulatory and policy recommendations to foster mobile broadband coverage in developing countries. Technical report, GSMA Association, Squire Patton Boggs, 2018.

96. Hasan, S.; Heimerl, K.; Harrison, K.; Ali, K.; Roberts, S.; Sahai, A.; Brewer, E. GSM whitespaces: An opportunity for rural cellular service. 2014 IEEE International Symposium on Dynamic Spectrum Access Networks (DYSPAN), 2014, pp. $271-282$. doi:10.1109/DySPAN.2014.6817804.

97. Dhungana, A.; Bulut, E. Peer-to-peer energy sharing in mobile networks: Applications, challenges, and open problems. Ad Hoc Networks 2020. doi:https://doi.org/10.1016/j.adhoc.2019.102029.

98. LTE Aerial Profile v1.00. Technical report, GSMA, GUTMA, 2020.

99. 3GPP. 3GPP Regulation for UAS-UAV. https://www.3gpp.org/uas-uav, 2019.

100. UAS Traffic Management Architecture. Technical report, GUTMA, 2017.

101. Designing UTM for Global Success. Technical report, GUTMA, 2020.

102. Alastair Westgarth. Saying goodbye to Loon. https://medium.com/loon-for-all/loon-draft-c3fcebc11f3f/, 2021.

103. Yael Maguire. High altitude connectivity: The next chapter. www.engineering.fb.com/2018/06/27/connectivity/ high-altitudeconnectivity-the-next-chapter/, 2018. 